\title{
The Role of the School MIS in Pupil Transfer Within England
}

\author{
Alan Strickley and Sue Allen \\ Birmingham City Council, UK
}

\begin{abstract}
Transfer is a stage at which the education of pupils can be detrimentally affected if continuity of the curriculum and programmes of learning are not seamless and appropriate to the learner. As such the movement of the pupil profile is key. This paper looks at the current data transfer model and considers its strengths and weaknesses in the context of primary, secondary and in year admissions. It considers solutions that would optimise the availability, quality and accessibility of the process and the viability of each. It concludes that an improvement would be best facilitated by an investment in the technological infrastructure and hence recommends a shared database with web-enabled access to all appropriate parties.
\end{abstract}

Keywords: Management information systems; common transfer file; pupil transfer; curriculum continuity; admissions

\section{BACKGROUND}

The transfer of pupils from one school to another was identified by the Department for Education and Science (DES, 1987) as a time at which curriculum continuity and progression of individual pupils is most at risk. As Capel, Zwozdiak-Myers \& Lawrence (2007) suggest whilst the introduction of the National Curriculum (NC) has helped to create more continuity in schools in England it is not promoted consistently during transfer, particularly from primary to secondary schools (secondary admissions).

The report 'Changing Schools' (OFSTED. 2002) found, amongst its conclusions, that whilst there was a recognition that good arrangements for transfer were important, that there was variation in the quality of information generally leading to additional testing in year 7. While the report accepted that the Common Transfer Form as it was then and more currently Common Transfer File or CTF (DCSF, 2007a) for Key Stage 2 (KS2) information was

Please use the following format when citing this chapter:

Strickley, A. and Allen, S., 2009, in IFIP International Federation for Information Processing, Volume 292; Evolution of Information Technology in Educational Management; Eds. Tatnall, A., Visscher, A., Finegan, A., O’Mahony, C., (Boston: Springer), pp. 129-142. 
an improvement, they also found that very few primary schools provided information over and above the KS levels and test scores. At this time they commented that there was a lack of non-core subject records, curricular targets and exemplar work and that very few used electronic transfer mechanisms.

School Management Information Systems (MISs), although lacking in some of the more knowledge-based information, do contain a large amount of data about the pupil within the school. In addition most of the information is structured for easy access and analysis. The transfer of this data would seem a logical step as an agent to improve this critical transitional stage as well as at any other stage of transfer for the pupil.

However the way that the MISs are structured in the current educational setting causes some problems in this respect. In most other MISs once data is input it remains in that source database for the duration of its useful life. As such it is always available for informed decision making to those with appropriate access.

The situation for school MISs is different in so much as the information about the pupil is held at the school currently attended and the pupil will change schools at least once in their educational life. This change will be at admission to secondary school and may occur at several other times within a single phase as an in year (or casual) transfer. In an area with high mobility, such as is increasingly being observed in urban settings, the in-year change can happen many times during a pupil's education.

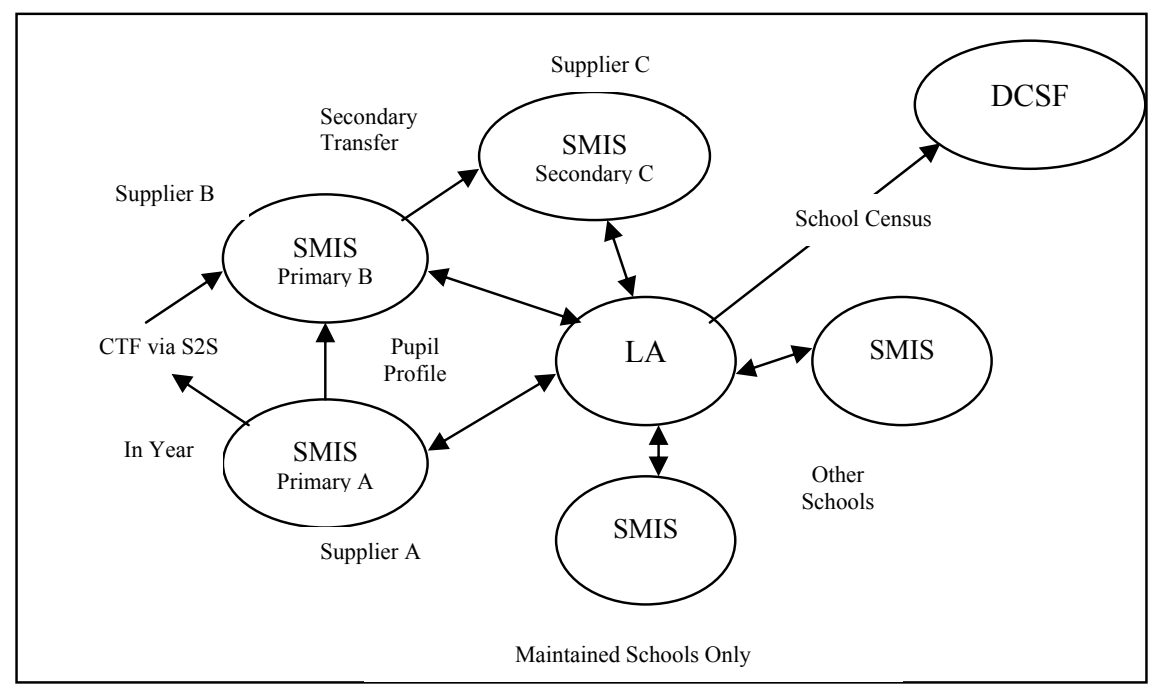

Figure 1

Figure 1 attempts to illustrate this complex arrangement. The outer circles represent Local Authority (LA) maintained schools. These may be of any type including nursery, primary and secondary. Each school has its own self-contained schools management information system (SMIS) which may be from any of a number of commercial suppliers or a system bespoke to the 
school or the whole LA. Secure data transfer will occur between the schools and the LA on a regular basis for a variety of purposes including School Census (DCSF, 2008c) and the population of the central LA children's database (see section 4).

Transfer of validated school data from school census will occur from the LA to the Department for Children Schools and Families (DCSF) on a termly basis. DCSF will return data to the LAs and schools but this will generally be via portals such as RAISEOnline (OFSTED, 2008) and Key to Success websites (DCSF, 2007e) hence the arrow is one way only.

Each school in the LA will build up a profile of the pupils within in its care and much of this data will be entered into the MIS. Such data items are discussed later in this section.

The figure shows the transfer of a pupil from a primary school A to a different primary school B as an in year transfer possibly as a result of the parents moving home. Data about the pupil is transferred from school A to B via the secure DCSF School To School (S2S) web portal (DCSF 2007d) as a CTF (see sections 5 \& 6).

A subsequent transfer from primary school B to a secondary school C as a secondary transfer will generally be via the LA and is described in Section 3.

With an increase in statutory returns and as a result of more strategic MIS modules (e.g. assessment, attendance, Special Educational Needs Coordinator (SENCO) etc.) the schools' MISs are containing more and more vital information about the pupils' programmes of learning, pastoral issues and other related data. As such the transfer of this data with the pupil as they move from school to school is vital to enable a seamless transition from one learning environment to the next. This is a system of data transfer envisaged by Smith \& Wild (2001) and Nicholls \& Gardner (1999).

Such a transfer of data will enable learning programmes and resources within the school to be tailored more specifically to the needs of the pupil. As the quotation below, from the recently published governmental children's plan (DCSF, 2007f), illustrates:

"Personalised learning will ensure that information about the child's academic progress and their personal development at primary school will be passed on to the secondary school to ensure continuity." (p.57)

Therefore we have a position in which the data appertaining to a pupil needs to move from the existing school (sender) to the school to which the pupil is moving to (recipient). This creates several problems and opportunities as this paper attempts to investigate.

As a tool for evaluating the effectiveness of the transfer of pupil data we will focus on the three Cs of the process. These are; the consistency (how uniformly is it applied?); the conduit (how effectively is it transferred?); and the content (what is transferred?) of the data transfer process.

For the purposes of this paper we will be considering the transfers of pupils to primary school (primary admissions), from primary to secondary 
(secondary admissions) and in year. Whilst some LAs in England have a system with first, middle and high schools the situation is similar although the ages of the pupils are different.

\section{PRIMARY ADMISSIONS}

In many cases the admission of pupils to primary school will be the first point of entry for the pupil into the educational system. As such there will be no previous learning programmes available to transfer. In some cases the child may have attended nursery school, however many of these do not have a school MIS. Many primary schools have nursery classes attached to their main primary school and share a single MIS so transfer is not an issue. In any case most pupils will only have received one year of education prior to transfer (and at a very early age) hence the amount of detailed information regarding the child will be less than for secondary transfer. As such whilst the basic premise regarding data transfer applies the effects on the pupils are likely to be less significant.

\section{SECONDARY ADMISSIONS}

The transfer of pupils from primary to secondary school constitutes the major movement of pupils in an LA and consequently is a well researched area from the perspective of the effects on the transferring pupils. For example, Derricott (1985); Galton \& Willcocks (1983); Gorwood (1991); Schagen \& Kerr (1999); Galton Morrison \& Pell (2000). All of them suggest that transfer has an effect on the pupil.

Currently in England, since the introduction of the admissions code of practice (DfES $2002 \&$ 2007) secondary admissions is coordinated by the LA that the pupil resides in.

Briefly the process involves the LA collecting school preference information from the parents either on a paper form or online and allocating schools to the highest available preference on a formula-based criteria, as defined by the admitting authority, where schools are oversubscribed.

The importance of the process is that on allocation day (March 1st of the year of admission to the new school) the LA holds data appertaining to all of the pupils allocated to its secondary schools for the following September. As a minimum this will be the information supplied by the parent i.e. name, address, date of birth etc. but with the advent of the children's database, held at the LA, it may contain considerably more. As such the children's database requires further discussion. 


\section{CHILDREN'S DATABASE}

Since the implementation of the Department for Education and Skills' (DfES') Information Management Strategy (IMS) in 1998 (DCSF, 2008a) and more recently the Every Child Matters legislation (HMSO, 2003) together with the reducing the bureaucratic burden on schools (Implementation Review Unit (IRU), 2003; 2005) most LAs will have a central database of all of the pupils within its maintained schools (although not those in the independent sector).

These databases are normally populated from the schools' MISs via weekly, monthly or termly data feeds and will contain a subset of the pupil data within the schools. Precisely what will be held will depend on the LA requirements and the systems being used.

As such after allocation day the LA has the capacity to send electronically information about each pupil to its new school. Exactly what it sends and how is the focus of the next section.

\section{THE COMMON TRANSFER FILE (CTF)}

The CTF was introduced by the DfES in 2000 (DCSF, 2007a) originally as a paper form and subsequently in 2002 as an electronic xml file. It is a statutory requirement, within the pupil regulations (HMSO, 2005; DCSF, 2007b) for the governing body of the sender school to create this file and send it on to the recipient school within 15 days of the pupil leaving.

The CTF has been through several updates during its existence and is currently in version 7 i.e. CTF7. The full specification for the CTF may be found at the Department for Children, Schools and Families Teachernet website (DCSF, 2007a). The key data items held are: sending and receiving school names; basic pupil information (Date of Birth (DOB), name, ethnicity, NC year group etc.); SEN information including previous history (level, need, supplementary information), contact address information, contact information, (telephone, responsibility etc.), school KS information (Foundation Stage, KS1, KS2 and KS3 down to component level); school history, am-pm level attendance data and aggregate attendance information. This list is a subset of the data which can be usefully stored against a pupil in even the most basic MIS. However it should be noted that most of the above data items are not mandatory.

With the information the LA has in its children's database and the list of allocated schools within its admissions system the LA is able to send a CTF for each of the pupils that will be attending their new secondary school in September. In fact most do this soon after allocation day in addition, or as a replacement, to electronic or paper lists.

For the purposes of this particular transfer the DCSF developed the Admission Transfer File (ATF). The ATF is equivalent to CTF with regards to basic pupil data except that it does not require a Unique Pupil Number 
(UPN) (DCSF, 2007g) as a mandatory field as this may not be available within the LA admissions system. Since 2007 the ATF (DCSF, 2007c) has had all non-core pupil data elements removed and as such the CTF will be the predominant file discussed in this paper. The onus is now on the primary school or secondary school to obtain these non-core elements from the Key to Success (DCSF, 2007e) website.

What the LA actually sends will depend upon what it has in its children's database. Some LAs have all of the data that the CTF can hold including assessments and attendance whilst others only have basic pupil data. The $\mathrm{CTF}$ can be sent as many times as required as an update file and hence KS2 assessments can be sent after the tests have been marked in the July before the pupils' entry to the secondary school.

\section{THE SCHOOL TO SCHOOL SECURE WEB SITE (S2S)}

The original paper-based CTF could be transferred from school to school via surface mail, by internal LA post or even in an envelope via the transferring pupil. With the advent of the electronic version there was a tendency by some schools to attach the CTF to an email via a public server or send on a diskette through the mail. Neither of these methods are secure and are in breach of the Data Protection Act (HMSO, 1998) and the Pupil Information Regulations (HMSO, 2005).

As a response to this issue the DFES set up a secure web site with the primary purpose of facilitating the transfer of the CTF (although since its inception it has been developed to service the transfer of other files).

Basically the process required for a school to send or receive a CTF is as follows. Firstly the school will need to register itself or a specified user with a password and user name to log into the site (DCSF, 2007d). This registration process will ask for basic details including a contact email address.

For each recipient school a CTF will need to be created, through the MIS, by the sender school for the pupil(s) moving to that school. If the recipient school is unknown a special CTF can be created which indicates this.

To transfer the CTF the school user will need to log onto the S2S web site and upload the CTFs through a simple menu driven system. The file name of the CTF contains information about the sending and recipient school based on a unique combination of the LA number and school establishment numbers and will be stored in the S2S database for downloading by the appropriate school.

An email message will be sent to the appropriate registered users of the recipient school should a CTF be uploaded onto the S2S site based on the registration information given above. To download the file the school will 
perform a logon process similar to the above, download the appropriate file(s) and then import them into their MIS.

CTFs that have no recipient school will be uploaded into the 'lost pupils database'. These will normally be the responsibility of the LAs to check on a regular basis in an attempt to resolve the issues of missing pupils.

The site works well in technical terms. However as can be seen from the above it does involve considerable interaction from the schools in terms of producing the CTFs in the first place to logging onto the system and then uploading the files. A similar process for downloading is then required for accessing and importing the CTFs. Any process that relies on such high interactivity is likely to be used less frequently than a seamless one particularly when the uploading process generates no immediate net gains for the school involved and the download process relies on an accurate and up to date email contact address which may not always be the case.

As such the process is subject to the adoption by the schools who by their very nature are busy places with such tasks often seen as lower priority. The result is that when a new pupil arrives the CTF has not always been sent by the sender school and the recipient has to type in the data manually. Hence faith is lost in the system which results in less CTFs being uploaded and the effect is a loss of faith in the process.

\section{IN-YEAR ADMISSIONS}

Many LAs do not coordinate admissions in year and as such the transfer of information about the child via the CTF takes on even greater importance. Basically parent/carers will liaise with the school directly, either via advice from the LA, if new to the area, or completely independently if locally based.

Upon admission to the new school the transfer of the pupil information from the old school should be via the CTF. Whilst there is a statutory obligation for this to occur it is known that it does not always happen. Basically there are six possible reasons for this:

1. The LA may not have a secure school to school transfer system and the sending school may not be aware of, or wish to use, the National S2S secure data transfer system (DCSF, 2007d).

2. Even if a secure inter-LA system exists and is used, if the child is transferring to a school outside of the LA such a system will be ineffective. The issues in 1 above will apply to the use of the S2S site which does allow inter-LA transfer.

3. In some cases the new school that the pupil is transferring to is not known. Therefore unless the S2S system is used to place the record in the 'lost pupils area' the transfer will not take place.

4. It may be a period of time before the school is notified that the pupil has left and by the time the CTF has been created and sent by 
the sender school the recipient school will have collected and entered the data manually.

5. Schools in the independent sector are not included in any statutory regulations and hence transfer between themselves and the maintained sector is unstructured.

6. The transfer to schools outside of England, whilst currently covered by the regulations (DfES, 2005) from 2005/6, is not currently commonplace via the CTF and S2S website.

Whilst in year admissions affects less pupils than primary and secondary transfer for those that it does affect the availability of data from their previous school is important. Clearly a pupil moving on their own to a new school needs to settle in quickly to enable their learning to proceed with as little disruption as possible. For this to occur the school needs information about the pupil's prior education at their time of admission or ideally beforehand.

\section{ISSUES}

The transfer of pupil data via the CTF is a step in the right direction but is limited in several areas:

1. Whilst CTF7 contains considerably more information than the original file or form (CTF1) it still lacks the rich data that is required to plan the pupils' education from day one at the new school.

2. Although most LAs will transfer a CTF to the secondary school as part of the allocation process the children's database may only contain limited information about the child with which to populate it.

3. LAs generally only transfer the data once even though the CTF allows partial files for update purposes. This will generally be before KS2 results are known.

4. Some schools do not use the CTF, for the reasons given earlier in section 6, even though it is a statutory requirement (Keane, 2005).

With reference to the three $\mathrm{C}$ approach discussed in section 1 we can see that the process is not consistent and that the existing conduit is userintensive requiring actions at both the sender and recipient schools. This is particularly true for pupils changing schools as an in year transfer. In all cases the content is a small subset of the data that may be potentially held within a school's MIS appertaining to the pupil's profile. 


\section{SOLUTIONS}

There are a number of possible solutions to these issues each with its own advantages and disadvantages as discussed below:

\subsection{Increasing the data items transferred in the CTF}

These could include items which are contained in many schools' MISs but are not in the current CTF: positive and negative behaviour records including all types of exclusions; the Qualifications and Curriculum Authority or National Foundation for Educational Research optional test results (where administered); medical and social issues; more detailed SEN information such as Individual Education Plans, interventions etc.; pupil end of term reports; other free text fields.

However even if the CTF were to contain everything in a school MIS it would still be lacking schemes of work, preferred learning style etc. together with some of the more tacit data generally not held on the school MIS.

Whilst it could be argued that much of the above is transferred as hard copy from school to school this is not always the case as observed by Schagen \& Kerr (1999) in which one in three of the secondary schools surveyed did not receive even the basic information from their feeder schools. Also the unstructured format of this paper-based information often means that it is not looked at or used by the receiving school (Brown et al. 1996; OFSTED 1998).

The electronic transfer of data in a structured format would help in the development of learning plans for the new intake as Capel, ZworzdiakMyers \& Lawrence (2007) found in their study into transfer from primary to secondary school.

Whilst there are some clear advantages to extending the facilities of the existing CTF infrastructure with its statutory status, this solution still suffers from the inherent problems of schools not transferring the file (particularly for in year) and the lack of KS2 data from the LA at secondary transfer.

\subsection{A central shared database}

The creation of a single LA database, which is accessed by the schools through a web-enabled ePortal, would facilitate the removal of the process of physical file transfer. Such a system would ensure that the data at both school and LA was concurrent by essentially creating a single LA-wide database.

A local copy of the data at the schools would ensure processor-dependent tasks such as timetabling and analysis were not affected by bandwidth and downtime.

Regional groups of LAs could be connected through regional portals connected together to create a national system. This would create a model similar to that to be introduced by Contact Point (HMSO, 2007). 
The resultant system could support the sharing of tacit knowledges across school communities in a Community of Practice type approach (Skyrme, 2002).

Additional advantages would be that files would not need to be physically transferred, unless moving outside of the LA and local and central government audits could be carried out remotely (IRU, 2005).

Unfortunately with the onus on school autonomy, supplier commercial interests and less LA intervention there is not currently the political will for such a model. In addition a lack of confidence in the technical infrastructure to implement such an arrangement makes it unlikely in the short term. However a pilot in Scotland (Capita, 2007) utilising just such a method for small schools and the more recent national intranet GLOW (GLOW, 2008) will be monitored with interest.

\subsection{The regular update from schools' MISs}

Some LAs do implement a similar model to the above in which they exchange data on a regular basis. For LAs and schools that use the same supplier systems this can be done seamlessly and with a large number of data items. For others the CTF is often the transfer vehicle with the same inherent problems as in 8 above, limiting the data items transferable.

Such an option enables the LA to deliver better information at secondary transfer but still does not improve the in year situation as this is outside of the LA coordination process. Problems with reconciliation between school files and the LA database, particularly with address information, also constrain its effectiveness.

\subsection{Software Interoperability Framework (SIF)}

The implementation of an automatic, interoperability data structure could remove many of the problems identified above. The SIF Association (SIFA UK, 2007) provides the detail of this process. However it basically specifies the data to be transferred and the agents to transfer them with, via a zone integration server or ZIS, to the appropriate recipient.

Such a method may still only offer the transfer of defined data items leaving some of the important textual items to be transferred by hard copy as with the current situation.

\section{ACCESS}

Whatever solution is selected there still remains the issue of access. Assuming that information about the pupils is transferred to the new school, how easily will the staff at the school have access to that data? Strickley (2004; 2007) would suggest that, particularly in primary schools, access is 
severely restricted. This lack of access will affect not just the information retrieval but also the recording of pupil data in the first place.

Such restrictions would also inhibit the use of data from within the school i.e. transition from one year to the next, an area less widely researched but according to Galton, Gray \& Ruddick (1999 \& 2003) still having a significant impact.

\section{SUMMARY AND CONCLUSIONS}

The movement of pupil data between schools is important for the continuity of education at all stages of transfer. The content and method of transfer are of particular interest.

Whilst the CTF has made a significant improvement there is a lack of uniformity in the transfer of this file as well as a serious deficiency in content that is needed to assist continuity of learning for the transferring pupils. The lack of transfer of anything at all by some schools is of particular concern.

There are a number of options available each realising benefits as well as having some constraints.

Whilst it is unlikely that it is possible to have too much information on the pupils previous learning, much of this information needs to be structured so that it can be easily analysed by the receiving school.

Once received it is important that the correct staff have the required access to the information for both input and retrieval.

The web-enabled central database provides the preferred option as it not only gives concurrent and representative data but also allows seamless data transfer at point of entry as well as the option to share tacit information. However even this model will need a change in central policy if independent schools and those outside of England are to be fully integrated into the system.

This model in which structured data can be used to give a thumbnail sketch of the pupils' learning together with an ability to drill down into more detailed and rich information, perhaps interacting electronically with relevant teachers, would support the continuity of learning for the pupil.

The Admissions Code of Practice (DfES, 2007) having been revised in 2007 is currently in the consultation phase for changes (DCSF, 2008b) which would affect the 2010/2011 admissions round. The inclusion of in year coordination for LAs in these draft regulations could potentially address some of the issues regarding the consistent and improved transfer of the CTF for these pupils but not the content of the CTF itself.

As a result of the British Educational Communications and Technology Agency (BECTA, 2005) value for money document and resultant memorandum of understanding with software suppliers, the SIF proof of concept stages 1 and 2 have been commissioned (SIFA UK, 2007). In particular one of the objectives of the stage 2 in Northern Ireland is 'to 
establish SIF as a possible solution for data interoperability for assessment' which is of particular relevance to the transfer of the pupil profile as discussed in this paper.

Strickley (2007) reports, from his case study of Birmingham primary schools, a quotation from an office administrator which sums up the situation with regards to the original paper-based CTF and equally to the more recent electronic file concisely:

"The transfer form doesn't give enough information either." ( $p$. 253)

If we are to move to a situation where we are effectively using the MIS to support the transfer of pupils the next few years will be crucial.

\section{REFERENCES}

Brown, J. M., Taggart, B. McCallum, B \& Gipps, C. (1996). The impact of key stage 2 results. In Education 3 to 13, Volume 24, No. 3, (pp. 3-7).

BECTA (2005). School management systems and value for money. Coventry: BECTA.

Capel, S., Zwozdiak-Myers, P. \& Lawrence, J. (2007). The transfer of pupils from primary to secondary school: a case study of a foundation subject: physical education. Research in education. 77: (pp. 14-30). Manchester: Manchester University press.

Capita. (2007). ONE in Scotland. [Online] http://www.capitaes.co.uk /EMS/Scotland.asp [Accessed 18 December 2007].

DCSF (2007a). CTF Definition. [Online]. http://www.teachernet.gov.uk/ management/ims/datatransfers/CTF/ctf7/ [Accessed 18 December 2007].

DCSF (2007b). Information on the transfer of CTF. [Online] http:// www.everychildmatters.gov.uk/resources/ig00202/ [Accessed 18 December 2007].

DCSF (2007c). ATF Definition (2007). [Online] http://www.teachernet. gov.uk/management/ims/datatransfers/coordadmissions/CoorAdmin2008 / [Accessed 18 December 2007].

DCSF (2007d). S2S File transfer site. [Online] http://www.teachernet. gov.uk/management/ims/datatransfers/s2s/ [Accessed 19 December 2007].

DCSF (2007e). Key to Success website. [Online] https://www.keytosuccess. dfes.gov.uk/ [Accessed 19 December 2007].

DCSF (2007f). The children's plan. Norwich: The Stationery Office.

DCSF (2007g). Unique pupil numbers; policy and guidance practice for schools and Las. [Online] http://www.teachernet.gov.uk/management/ $\mathrm{ims} /$ datamanagement/UPN/ [Accessed 23 November 2007].

DCSF (2008a). Information management strategy. [Online] http://www. teachernet.gov.uk/management/ims/ [Accessed 27 March 2008]. 
DCSF (2008b). School Admissions Consultation 2008. [Online] http://www. desf.gov.uk/consultations/conDetails.cfm?consultationId=1561 [Accessed 3 July 2008].

DCSF (2008c). School Admissions Consultation 2008. [Online] http://www. teachernet.gov.uk/management/ims/datacollections/sc2009/ [Accessed 5 August 2008].

DES (1987). The curriculum from 5 to 16: Curriculum matters 2. London: HMSO.DfES (2002). Admissions Code of Practice (2002). London: TSO.

DfES (2005). Explanatory memorandum to the education (pupil information) (England) regulations 2005; 2005 No. 1437. London: HMSO

DfES (2007). Admissions Code of Practice (2007). London: TSO.

Derricott, R. (1985). Curriculum continuity: primary to secondary. Windsor: NFER-Nelson.

Galton, M. \& Willcocks, J. (Eds.) (1983). Moving from the primary classroom. London: Routledge \& Kegan.

Galton, M., Gray, J. \& Ruddick, J. (1999). The impact of school transitions and transfers on pupils' progress and attainment. London: DfEE.

Galton, M., Gray, J. \& Ruddick, J. (2003). Transfer and transition in the middle years of schooling (7-14). London: DfES.

Galton, M., Morrison \& Pell. (2000). Transfer and transition in English schools: reviewing the evidence. International Journal of Educational Research. 33: (pp.341-363). Cambridge: Elsevier

GLOW (2008). [Online]. http://www.glowscotland.org.uk/ [Accessed 27 March 2008].

Gorwood, B. (1991). Primary-secondary transfer after the national curriculum. London: Croom Helm.

HMSO (1998). Data Protection Act. [Online]. http://www.opsi.gov.uk/acts /acts1998/ukpga_19980029_en_1 [Accessed 06 August 2008].

HMSO (2003). Every Child Matters. Norwich: TSO.

HMSO (2005). Statutory Instrument 2005 No. 1437

The Education (Pupil Information) (England) Regulations 2005. Norwich: TSO

HMSO (2007). ContactPoint. [Online]. http://www.everychildmatters.gov. uk/deliveringservices/contactpoint/ [Accessed 04 January 2007].

Implementation Review Unit (IRU) (2003). tackling Bureaucracy in schools: Interim report. DfES/0830/2003. Nottinghamshire: DfES Publications.

IRU (2005). The revised edition of the Protocol on Data Sharing and Rationalisation in the Schools Sector. [Online]. www.teachernet.gov.uk/ management/ims/newsinfo/protocol/ [Accessed 20 December 2007].

Keane, T. (2005). CTF Usage in Schools [Online] www.teachers.gov.uk/ doc/8603/CTF_DCSR 0705.ppt [Accessed 18 December 2007].

Nicholls, G. \& Gardner, J. (1999). Pupils in transition. London: Routledge. 
OFSTED (1998). How teachers assess the core subjects at key stage 3. London: OFSTED.

OFSTED. (2002). Changing schools: an evaluation of the effectiveness of transfer arrangements at age 11. London: OFSTED.

OFSTED. (2008). RaiseONLINE. [Online]. https://www.raiseonline.org/ [Accessed 23 July 2008].

SIFA UK (2007). Home page. [Online]. http://uk.sifinfo.org/ [Accessed 18 December 2007].

Schagen, S. \& Kerr, D. (1999). Bridging the gap? The national curriculum, and progression from primary to secondary school. Slough: NfER.

Skyrme, D. (2002). Knowledge management: approaches and policies. [Online] $\mathrm{http} / / / \mathrm{www} . p r o v i d e r s e d g e . c o m / \mathrm{docs} / \mathrm{km}$ _articles/KM__Approaches_and_ Policies.pdf [Accessed 4 April 2006]

Smith, D \& Wild, P. (2001). The future of school information systems. In Visscher, A.J., Wild, P. \& Fung, A.C.W. Information Technology in Educational Management. (pp. 137-160). Netherlands: Kluwer.

Strickley, A., B. (2004). Factors Affecting the Use of MIS as a Tool for Informing and Evaluating Teaching and Learning in Schools. Education and Information Technologies 9 (1): (pp.47-66), March 2004. Boston, Dordrecht, London: Kluwer Academic Publishers.

Strickley, A., B. (2007). An evaluative case study of the use of management information systems in Birmingham primary schools. Doctoral thesis. Birmingham: Birmingham City University. 